IZA DP No. 9406

The Subversive Nature of Inequality:

Subjective Inequality Perceptions and Attitudes to Social Inequality

Andreas Kuhn

October 2015 


\title{
The Subversive Nature of Inequality: Subjective Inequality Perceptions and Attitudes to Social Inequality
}

\author{
Andreas Kuhn \\ Swiss Federal Institute for Vocational Education and Training, \\ University of Lucerne and IZA
}

Discussion Paper No. 9406

October 2015

\author{
IZA \\ P.O. Box 7240 \\ 53072 Bonn \\ Germany \\ Phone: +49-228-3894-0 \\ Fax: +49-228-3894-180 \\ E-mail: iza@iza.org
}

\begin{abstract}
Any opinions expressed here are those of the author(s) and not those of IZA. Research published in this series may include views on policy, but the institute itself takes no institutional policy positions. The IZA research network is committed to the IZA Guiding Principles of Research Integrity.

The Institute for the Study of Labor (IZA) in Bonn is a local and virtual international research center and a place of communication between science, politics and business. IZA is an independent nonprofit organization supported by Deutsche Post Foundation. The center is associated with the University of Bonn and offers a stimulating research environment through its international network, workshops and conferences, data service, project support, research visits and doctoral program. IZA engages in (i) original and internationally competitive research in all fields of labor economics, (ii) development of policy concepts, and (iii) dissemination of research results and concepts to the interested public.
\end{abstract}

IZA Discussion Papers often represent preliminary work and are circulated to encourage discussion. Citation of such a paper should account for its provisional character. A revised version may be available directly from the author. 


\section{ABSTRACT \\ The Subversive Nature of Inequality: Subjective Inequality Perceptions and Attitudes to Social Inequality*}

This paper shows that higher levels of perceived wage inequality are associated with a weaker (stronger) belief into meritocratic (non-meritocratic) principles as being important in determining individual wages. This finding is robust to the use of an instrumental-variable estimation strategy which takes the potential issue of reverse causality into account, and it is further corroborated using various complementary measures of individuals' perception of the chances and risks associated with an unequal distribution of economic resources, such as their perception of the chances of upward mobility. I finally show that those individuals perceiving a high level of wage inequality also tend to be more supportive of redistributive policies and progressive taxation, and that they tend to favor the political left, suggesting a feedback effect of inequality perceptions into the political-economic sphere. Taken together, these findings suggest that high levels of perceived wage inequality have the potential to undermine the legitimacy of market outcomes.

JEL Classification: D31, D63, J31

Keywords: inequality perceptions, attitudes to social inequality, support of redistribution, legitimacy of market outcomes, beliefs about the causes of economic success, political preferences

Corresponding author:

Andreas Kuhn

Swiss Federal Institute for Vocational Education and Training

Kirchlindachstrasse 79

3052 Zollikofen

Switzerland

E-mail: andreas.kuhn@ehb-schweiz.ch

\footnotetext{
* I thank Hans Pitlik, Justina Fischer, Alois Stutzer, and several participants at the 2013 Annual Meeting of the European Public Choice Society for helpful comments and suggestions on an early draft of this paper, and Sally Gschwend-Fisher for proofreading the manuscript.
} 


\section{Introduction}

Many OECD countries have seen significant increases in inequality in the past few decades, including the United States as well as several continental European countries (e.g. Atkinson, 2008). Besides their direct and obvious impact through the re-allocation of economic resources to and from different socio-economic groups, changes in a country's aggregate distribution might also have repercussions in the political-economic sphere if they influence individuals' beliefs about the legitimacy of market outcomes. Indeed, several theoretical papers (e.g. Alesina and Angeletos, 2005; Alesina et al., 2012; Bénabou and Tirole, 2006) made a convincing argument that changes in the aggregate level of inequality might influence individuals' attitudes towards social inequality, such as their beliefs about the importance of non-meritocratic principles in determining individual wages, and that these changes in attitudes might eventually feed back into the effective distribution of economic resources because they might affect distributional parameters ultimately set by voters, such as marginal tax rates on income.

The goal of this paper is to directly test the hypothesis that inequality affects the legitimacy of market-based outcomes. The paper presents, against this broader background, empirical estimates of the effect of individuals' subjective perceptions of wage inequality in their country of residence on their attitudes to social inequality, focusing on individuals' subjective beliefs that meritocratic, or non-meritocratic, factors are important in determining wages. In contrast to most previous studies on the topic, however, this paper focuses on a broad array of attitudes the perceived level of inequality potentially affects, rather than only on a single attitudinal measure. ${ }^{1}$ The second key feature of this study is that the empirical analysis is based on an individual-level measure of subjective inequality perceptions, rather than on some objective and highly aggregated measure of inequality. Using a unique measure of individual-level perceptions of wage inequality, I find that higher levels of perceived inequality are significantly and substantively associated with a stronger (weaker) belief in labor markets functioning according to non-meritocratic (meritocratic) principles. In this sense, a higher perceived level of wage inequality indeed appears to subvert the legitimacy of market outcomes. This result holds true

\footnotetext{
${ }^{1}$ While previous evidence has mostly focused on the impact of inequality on subjective wellbeing, both Bjørnskov et al. (2013) and Schneider (2012) have argued that the perceived fairness of the wage distribution mediates the effect of inequality on wellbeing, suggesting that a focus on a broader set of outcomes might yield interesting insights into the overall attitudinal effects of inequality. Note, however, that neither of these studies has estimated the direct effect of inequality (perceptions) on attitudes.
} 
when I account for potential reverse causality using an instrumental-variable approach, and I further corroborate it using a variety of complementary outcomes reflecting an individual's perceptions of the chances and risks associated with an unequal distribution of wages, his or her attitudes towards the role of government and progressive taxation, as well as his or her general political preferences. In line with the results for individuals' beliefs about the reasons for getting ahead, these additional estimates show that higher inequality perceptions lead to a stronger (weaker) awareness or salience of the risks (chances) potentially associated with inequality, as well as a stronger support of government intervention aiming to reduce existing inequalities, of progressive taxation, and of the political left. Finally, and importantly, I also find that those individuals with higher inequality perceptions are less satisfied with their own wages. $^{2}$

The key conceptual challenge in addressing these questions empirically is the need for an individual-level measure of inequality perceptions. Simply relying on a more or less easily available objective, yet also highly aggregated, measure of inequality would ignore the fact that people appear to hold widely different, and often heavily biased perceptions of the overall distribution of economic resources (e.g. Chambers et al., 2014; Cruces et al., 2013; Kuhn, 2011; Norton and Ariely, 2011; Osberg and Smeeding, 2006). ${ }^{3}$ If we acknowledge that individuals have different, and presumably biased, perceptions of wage inequality, the use of an objective measure of inequality in the empirical analysis would simply fail to reflect heterogeneity of this kind, potentially implying inconsistencies in the estimated effect of inequality on attitudes. ${ }^{4}$ In fact, the available empirical evidence shows that individuals' perceptions of wage levels and/or inequality are, in part, directly related to socio-economic factors (e.g. Kuhn, 2011; Schneider, 2012), suggesting that part of the observed variation in individual-level (mis-)perceptions of inequality is indeed of a systematic nature (implying a potential bias when this source of variation is ignored when estimating the impact of inequality on attitudes). To take these

\footnotetext{
${ }^{2}$ This last finding is insofar especially important as it allows me to directly relate my findings to the existing empirical evidence on the subject which has, as discussed in more detail below, up until now almost exclusively focused on the association between inequality and individuals' subjective wellbeing (Senik, 2005, provides a survey of this literature).

${ }^{3}$ Other studies have focused on individual perceptions of alternative economic phenomena, such as tax rates (Gemmell et al., 2004) or corruption (Olken, 2009).

${ }^{4}$ There is, of course, also a more practical reason for favoring individual-level inequality perceptions over aggregate-level inequality measures. Because there is much more variation in individual-level inequality perceptions, it will presumably be easier to get reasonably precise estimates when using inequality perceptions rather than some objective measure of inequality.
} 
issues into account, the empirical analysis of this paper will therefore be based on a simple yet intuitive empirical measure of individual-level inequality perceptions, following the procedure proposed by and described in more detail in Kuhn (2011).

In contrast to the approach chosen in this paper, however, most previous papers studying the impact of inequality on individuals' attitudes used some objective, rather than subjective, measure of inequality as their key regressor - assuming, at least implicitly, that people correctly perceive the prevailing level of inequality. While earlier studies focused on highly aggregated measures of inequality (Verme, 2011, provides a survey of studies focusing on the association between country-level inequality measures and individual-level measures of subjective wellbeing), more recent studies have shifted their focus towards more disaggregated measures of inequality, arguing that people do not care as much about the aggregate distribution of market wages as they care about the comparison to smaller and much more specific reference groups, such as their coworkers, their friends, and/or their neighbors. ${ }^{5}$ The latter group of studies does allow for variation in inequality perceptions across individuals, but only because of different comparison groups, not because of biased perceptions of wages or wage differentials per se.

Remarkably, these studies consistently tend to find a negative association between inequality and subjective wellbeing, independent of the exact definition of the comparison group. ${ }^{6}$ For example, Clark and Oswald (1996) show in a sample of British workers that both job and wage satisfaction are significantly and negatively associated with an individual's comparison income, given by the predicted wage from a conventional wage regression, while holding the absolute level of income constant. Ferrer-i-Carbonell (2005) reports a similar result for Germany. She defines individuals with similar education, age, and location of residence as the comparison group and finds that well-being increases the larger an individual's income is with respect to that of the comparison group while holding the absolute level of income constant. Luttmer (2005), in contrast, matches individual-level survey data to information on local average household incomes from representative survey data from the US, using a strictly spatially defined comparison group. He finds that, even after controlling for an individual's own income, self-

\footnotetext{
${ }^{5}$ This lines up well with Clark and Senik (2010), who find that most individuals, if asked directly, confirm that such comparisons are at least somewhat important for them. Moreover, individuals most often compare themselves with their colleagues (i.e. their coworkers).

${ }^{6}$ Only few papers have directly focused on behavioral, instead of attitudinal, effects of inequality, such as on individual work effort. In contrast to the (much larger) literature focusing on subjective wellbeing, the findings are considerably more mixed (e.g. Charness and Kuhn, 2007; Clark et al., 2010; Cornelissen et al., 2011).
} 
reported happiness is lower the higher average earnings are in an individual's neighborhood. Clark et al. (2009), using a similar approach and using data from Denmark, show that subjective well-being depends on one's relative rank within narrowly defined neighborhoods. Similarly, Schwarze and Härpfer (2007) report a negative relation between pre tax-and-transfer inequality and life satisfaction across regions in West Germany, while Winkelmann and Winkelmann (2010) report a negative association between aggregate-level inequality measures and economic wellbeing across municipalities in Switzerland as well.

The assumption that people have unbiased perceptions of the prevailing level of inequality has, however, been relaxed in two more recent studies. Both studies manipulate individuals' information about wage differentials in a field experiment. Both studies provide indirect evidence of people potentially having misperceptions of the true level of inequality, since a minor information treatment is able to influence individuals' attitudes. In the first of these studies, Card et al. (2012) randomize the access to information about coworkers' wages in a sample of university employees, providing arguably more compelling evidence on the causal effect of coworkers' wages on one's job satisfaction than most studies mentioned so far. Consistent with the evidence from the majority of observational studies, however, they also find that comparison income has a strong negative effect on individual job satisfaction. Finally, in another randomized field experiment, Kuziemko et al. (2015) manipulate individuals' information about income inequality. They find that providing individuals with this information has large effects on whether inequality is viewed as a pressing problem, but only small effects on individuals' support for governmental intervention with regard to the distribution of income.

Finally, yet on a somewhat more general level, this paper also adds to the small number of empirical studies documenting that economic events or circumstances influence individuals' attitudes and beliefs. In one of these studies, for example, Di Tella et al. (2007) show that granting property rights to squatters strongly influences their market beliefs. Similarly, Giuliano and Spilimbergo (2014) show that the macroeconomic context at the time of youth (i.e. growing up during a boom versus during a recession) influences individuals' beliefs about the importance of own effort and luck in getting ahead, their demand for redistribution, as well as their trust in public institutions. In line with the results from these studies, this paper shows that attitudes towards inequality are, in part, shaped by the prevailing level of inequality, and thus the paper 
also adds to our general understanding of how attitudes and preferences are formed and how they evolve over time.

The remainder of this paper proceeds as follows. The next section presents the data sources and discusses the selection of the sample as well as the construction of the key variables, i.e. attitudes to social inequality and individual-level inequality perceptions. Section 3 presents a few descriptives for the key variables. Section 4 discusses the econometric framework, while section 5 presents and discusses the resulting estimates. Section 6 concludes.

\section{$2 \quad$ Data and Measures}

\subsection{Data Source}

The empirical analysis fully relies on data from the "Social Inequality" cumulation of the years 1987, 1992, 1999, and 2009 (ISSP Research Group, 2014a,b). These data are a collection of several national-level surveys focusing specifically on attitudes to social inequality, administered and made available by the International Social Survey Programme (ISSP). ${ }^{7}$ They represent one of the best available sources of quantitative data to study individuals' perceptions of inequality and their attitudes to social inequality across countries and over time.

One of the key advantages of these data is that they cover a large number of observations from various countries and that they stretch over a relatively long period of time, for at least a subset of the participating countries (appendix table A.1 shows the number of individual observations by country and year). Another attractive feature of the data is that they contain a large number of items related to individuals' attitudes to social inequality, including, for example, individuals' beliefs about the causes of economic success or their stated support of progressive taxation. On the other hand, however, there have been many changes to the survey design over time, with the practical consequence that the number of items available in all four rounds of the survey is rather limited (more on this below; see sections 3.1 and 4.2).

\footnotetext{
${ }^{7}$ More information is available from the organization's website (www.issp.org). The data are available to researchers from the GESIS data archive (www.gesis.org/en/issp/home).
} 


\subsection{Sample Selection}

The sample used in the main part of the empirical analyses is determined by the availability of the dependent variable and the key regressor (i.e. individual-level inequality perceptions). As noted above, relatively few of the survey items are available in identical form in all four years of the survey. This implies that there are potentially large differences in the effective sample size for the different outcome measures, irrespective of any additional nonresponse issues. Fortunately, however, the series of items used to construct the key regressor are available in all four years (though not necessarily for all countries) in principle, but there have been a few changes over time to that set of items as well (cf. footnote 9 below).

\subsection{Attitudes to Social Inequality}

The following paragraphs discuss the various outcome measures available from the ISSP surveys (see also table 1, which contains the full list of survey items used as outcomes, and which is discussed in more detail in section 3.1 below).

\section{Beliefs About the Causes of Economic Success}

The outcome measures of primary interest are several attitudinal questions from the ISSP surveys which explicitly focus on individuals' beliefs about the causes of economic success. Overall, there are twenty-six different items dealing with individuals' beliefs on this issue, and they can be further grouped into three distinct sets of items describing different dimensions of individuals' beliefs about the causes of economic success, namely: (i) beliefs about the reasons for getting ahead, (ii) beliefs about the incentivizing effect of inequality, and (iii) pay norms. Note that the first two sets of items relate to individuals' perception of the wage-setting process, while the third set of items asks individuals about their normative views regarding the factors that should ideally be important in determining wages.

The first group of items asked individuals about the reasons, from their subjective point of view, for getting ahead in their country of residence. For example, one of the items in this group asked respondents whether they thought that coming from a wealthy family was important for getting ahead (here, as for most other items, respondents could indicate their agreement with the statement on a five-point scale running from one to five; see table 1 for details). Because 
this group of items contains variables describing both meritocratic (e.g. education and effort) as well as non-meritocratic (e.g. knowing the right people) mechanisms, an even more nuanced analysis of this specific dimension of attitudes to social inequality will be possible.

Then there are, secondly, several questions asking individuals' whether they believe that inequality has, at either the individual or the aggregate level, an incentivizing effect on economic actors. For example, respondents were asked whether they thought that wage differentials between people with different educational attainment are necessary as an individual incentive for choosing a higher educational attainment in the first place, or whether they thought that large differences in pay are necessary for a country's prosperity.

Finally, a third set of items asked individuals to state how wages should ideally be determined from their point of view. In other words, individuals were asked about their subjective pay norms (somewhat mirroring the first group of items, which asked them about the actual mechanisms determining pay). Here, for example, people were asked to state whether they thought that individual pay should be determined according to the attained level of education, or whether they would prefer compensation to depend on whether someone has to support children. As for individuals' beliefs about the reasons for getting ahead, it is also possible to distinguish between pay norms related to either meritocratic or non-meritocratic principles.

\section{The Perception of Chances and Risks Associated with Inequality}

A second broader subject the survey covers, composed of a total of eleven distinct items, describes individuals' perceptions of both chances and risks potentially associated, at least in respondents' perceptions, with economic resources being distributed more or less unequally. The main hypothesis here is individuals who perceive wage inequality to be higher will tend to perceive chances to be less obvious and risks to be more relevant than individuals who perceive inequality to be low.

A first item of interest in this context asked individuals whether they thought that they "stand a good chance of improving their standard of living", which might be thought of as a subjective measure of perceived upward mobility. One might hypothesize that those individuals who perceive a high level of inequality are, ceteris paribus, less likely to agree with this statement if they, as argued above, perceive that non-meritocratic factors drive wage differentials. That is, 
assuming that people perceive access to higher wages to be mainly driven by non-meritocratic mechanisms, it appears likely that those who perceive a high level of wage inequality are less likely to believe in their own upward-mobility.

Another potentially interesting outcome in this context is individuals' satisfaction with their own wages. Again, if individuals believe that wages are (co-)determined by factors beyond an individual's control, such as coming from a wealthy family or having well-educated parents, then we would probably also expect them to be less satisfied with their own wages (i.e. an individual's own compensation from work likely appears unfair, relative to those with higher wages, if higher wages are mostly achieved through factors not related to one's own ability or effort). ${ }^{8}$

A third item of interest describes individuals' normative assessment of the overall level of inequality (as they personally perceive it). In this regard, respondents were directly asked to state if they thought that "income differences are too large" in their country of residence. Note that the item does not ask about the perception of the absolute level of inequality, but about the perceived level of inequality relative to some legitimate level.

Fourth and finally, individuals were also asked to evaluate whether any broader conflicts exist in society from their point of view, such as between the poor and the rich, or between unemployed and employed workers. The hypothesis here is that a higher perceived level of wage inequality goes hand in hand with people being more likely to perceive more general conflicts between different socio-economic groups in their society.

\section{The Role of Government and Support of Progressive Taxation}

A further set of interesting items relates to the proper role of government towards redistribution and the provision of goods and services and to individuals' explicit support of progressive taxation. Again, if higher inequality perceptions are associated with a weaker belief in market justice, one would presumably also expect that higher inequality perceptions go hand in hand with a stronger support for government intervention and progressive taxation - to counteract the perceived malfunctioning of markets in the allocation of economic resources.

In the survey, individuals were asked with regard to the role of government to evaluate

\footnotetext{
${ }^{8}$ Also, as noted in the introduction, almost all of the previous empirical papers on the subject have focused exclusively on the association between inequality and some measure of wage or general satisfaction; this outcome thus also allows me to compare and relate my own results to that specific strand of the literature.
} 
whether they thought that the government is responsible for offering access to several goods and services such as providing a decent living standard for the unemployed. Regarding progressive taxation, individuals had to evaluate whether people with high incomes should pay higher taxes, or whether they thought that taxes for people with high income are high enough or not.

\section{Political Preferences and Political Participation}

Finally, the ISSP surveys also contain a few items on respondents' general political preferences; that is, their preferences towards either the political left or the political right, as well as their participation at the most recent national-level elections. I aggregate the three available items on political identification, as all three items ask about individuals' party preferences, and I use the remaining item on whether someone had voted at the last election in one's country as a rough measure of an individual's political participation.

\subsection{Inequality Perceptions and Distributional Norms}

\section{Inequality Perceptions}

One of the most distinguishing features of the ISSP data on social inequality is a series of questions about the level of compensation for people working in various specific occupations, such as an unskilled worker in a factory or a doctor in general practice. For each of these occupations, respondents in the survey were asked to estimate both the actual level of earnings as well as the level of earnings that they would consider as legitimate (actual and ethical wage estimates, for short, in the following). ${ }^{9}$

Noting that an individual's set of actual wage estimates roughly describes the wage differentials he or she perceives to exist, these wage estimates can be used to construct a simple yet highly intuitive measure of inequality perceptions at the level of the individual, denoted by $G_{i}^{\text {actual }}$ in what follows (see Kuhn, 2011, for additional details concerning the construction and interpretation of this measure). Put simply, though, $G_{i}^{\text {actual }}$ is probably best thought of as

\footnotetext{
${ }^{9}$ The list of occupations for which these individual wage estimates were elicited changed considerably over the different rounds of the survey. Fortunately, however, four specific occupations were part of this list in all four rounds of the survey; namely: (i) an unskilled worker in a factory, (ii) a doctor in general practice, (iii) a cabinet minister in the national government, and (iv) the chairman of a large national company. In the construction of individual-level inequality perceptions, I only use wage estimates for these four occupations to make the measure as comparable as possible over time.
} 
aggregating the information available in the set of actual wage estimates for any given individual into a single number and, in this sense, as roughly approximating an individual's perceived overall distribution of market wages. In fact, $G_{i}^{\text {actual }}$ is actually constructed in such a way that it has the same interpretation as a conventional Gini coefficient - with the key difference being that $G_{i}^{\text {actual }}$ does not describe the "true" (i.e. objectively measured) distribution of wages but the distribution of wages as perceived by individual $i$. Consequently, note that there is variation in the Gini coefficient because of its subjective nature - in contrast to the conventional, objective measurement of inequality where there is but one Gini coefficient for a given country and a given point in time - as long as individuals have different perceptions of what people in different occupations actually earn. This turns out to be true empirically, as mentioned in the introduction and as shortly discussed in section 3.2 below.

\section{Distributional Norms}

An analogous argument suggests that individuals' estimates of occupational wages that they judge as legitimate can be used to construct an individual-level measure of the legitimate level of inequality, denoted by $G_{i}^{\text {ethical }}$ in what follows. Similar to the individual inequality perceptions above, $G_{i}^{\text {ethical }}$ may be best understood as a rough summary measure of the wage distribution that a given individual $i$ judges as fair, based on his or her set of ethical wage estimates for people working in different occupations, and thus $G_{i}^{\text {ethical }}$ roughly reflects an individual's distributional norms. As the measure is constructed in the same way as individuals' inequality perceptions, it can also be interpreted as a Gini coefficient. In contrast to $G_{i}^{\text {actual }}$ however, $G_{i}^{\text {ethical }}$ describes a purely hypothetical situation, and thus there is no corresponding aggregate statistic as in the case of inequality perceptions.

Practically, it might be important to control for distributional norms when estimating the effect of inequality perceptions on attitudes towards social inequality because they are likely to have an influence individuals' attitudes to social inequality per se, and because previous empirical studies have shown that inequality perceptions and distributional norms are strongly correlated with each other (Kuhn, 2011). 


\section{Descriptives}

\subsection{Attitudes to Social Inequality}

Table 1 presents a few sample descriptives for the full set of outcome measures eventually considered in the empirical analysis below. Whenever possible, items were recoded in such a way that larger values indicate a stronger degree of agreement with the underlying question or statement from the survey. Note that a common issue across many of the items listed in table 1 is that they do not appear in all four rounds of the survey (section 4.2 below will discuss how I deal with this issue empirically).

\section{Table 1}

Panels (a) to (c) show descriptives for all the items describing an individual's beliefs about the causes of economic success, the functional role an unequal distribution of wages eventually plays, and about different pay norms. All related items are measured on a scale running from 1 to 5 . Interestingly, the mean values from panels (a) to (c) suggest quite unambiguously that people, on average, have quite a strong belief in the proper functioning of labor markets, as they tend to perceive meritocratic mechanisms to be considerably more important than nonmeritocratic ones. Specifically, mean item values for meritocratic principles are close to about 4 throughout, while averages for items asking about the importance of non-meritocratic principles are mostly below 3 (implying that these factors, on average, are not regarded as important in determining one's pay).

Consistent with this pattern, panel (d) shows that individuals also tend to believe that they have a good chance of improving their standard of living (mean item value of about 3, also on a scale taking on values between 1 and 5). Nonetheless, most people appear to be somewhat dissatisfied with their own wages, according to the mean values of the two items related to wage satisfaction, both equal to about 2.3 points (again on a scale running from 1 to 5 ). Next, panel (e) shows that an overwhelming majority of the sample perceives the income differences in their country of residence to be too large (mean item value of more than 4 on a scale from 1 to 5). This also appears to be reflected in the mean values for the items relating to the perception of conflicts within society, as the items most clearly related to groups with large income differentials appear to receive the strongest agreement. Generally, it appears that many 
people perceive a relatively high level of conflict in their societies (note that the scale runs from 1 to 4 only for the items in panel (e); the mean values of these items are therefore not directly comparable to the averages of the other items).

Descriptives for individuals' beliefs about the proper role of government, as well as their support for progressive taxation, are shown in panel (f). It is evident from the descriptives that a majority of the sample believes that the government should play a decisive role in the provision of a number of services, including the financing of education and the provision of social security (most items averaging values between about 3.6 and 4), and that most individuals are in support of progressive taxes as well (average agreement equal to 3.3 and 4, respectively).

Finally, panel $(\mathrm{g})$ shows that the average respondent in the pooled ISSP sample weakly tends to identify with the political left (here, the scale again runs from 1 to 5, with higher values denoting that an individual leans towards the political right). Finally, about $79 \%$ of the respondents state that they participated at the last elections. Below, I will use this item as a rough measure of an individual's level of political participation.

\subsection{Inequality Perceptions}

Panel (a) of table 2 presents descriptives for subjective inequality perceptions. In the overall sample, inequality perceptions average 0.56 Gini points with a standard deviation of about 0.218 (remember that inequality perceptions can, in principle, be interpreted the same way as a conventional Gini coefficient).

\section{Table 2}

The table also shows that very few individuals (less than one percent of the overall sample) perceive no wage differentials across the different occupations at all, resulting in $G_{i}^{\text {actual }}$ being exactly equal to zero. ${ }^{10}$ More important for the empirical analysis, however, note that there is huge variation in individual perceptions of wage inequality. This quite clearly shows that individuals really do have widely different perceptions of wage inequality, consistent with the

\footnotetext{
${ }^{10}$ Somewhat counterintuitively, the table also shows that there are a few observations with negative inequality perceptions. This results if an individual reverses the rank ordering of the occupations (with respect to their wages) for which subjective wage estimates are available, and which are used to construct individual-level inequality perceptions. Kuhn (2011) provides a more detailed discussion of this issue.
} 
literature mentioned in the introduction. This in turn implies that there might be large discrepancies between the effective level of inequality and the level of inequality individuals perceive. ${ }^{11}$ At the same time, the high intraclass correlation (about 0.395) suggests that inequality perceptions are quite strongly correlated with each other within country $\times$ year cells. Thus, there appear to be large differences in country averages of individual-level inequality perceptions, reflecting not only differences in the true level of inequality, but also differences in, for example, the way and intensity the issue of inequality is treated in the media.

\subsection{Other Individual-level Controls}

Panel (b) of table 2 shows descriptives for the other three individual-level controls used in the analysis below. The descriptives of age and gender are as expected, with a mean age of about 45 years and slightly more women than men in the sample. More interestingly, note how small the intraclass correlation for these two variables is - compared to inequality perceptions.

Finally, descriptives for distributional norms reveal, not surprisingly, that the legitimate level of wage inequality is considerably smaller than the perceived level. Also, the corresponding intraclass correlation shows that distributional norms are less strongly correlated within country $\times$ survey-year than inequality perceptions.

\section{Empirical Framework}

\subsection{Baseline Estimates}

To quantify the effect of inequality perceptions on individuals' attitudes to social inequality, I will estimate the parameters of a series of regression models that all share the following basic form:

$$
y_{i t}=\alpha+\beta G_{i t}^{\text {actual }}+\gamma x_{i t}+\psi_{j[i] t}+\epsilon_{i t}
$$

with $y_{i t}$ denoting attitudes to social inequality of individual $i$ living in country $j$ and having participated in the survey in year $t$, and with $G_{i t}^{\text {actual }}$ denoting an individual's perceived level of

\footnotetext{
${ }^{11}$ This, of course, also implies that there may be research contexts where simply working with objective data on inequality, instead of inequality perceptions, might be misleading.
} 
wage inequality in his or her country of residence. $\beta$ is the parameter of primary interest because it quantifies, under appropriate specifications of the model, the partial effect of inequality perceptions on individuals' attitudes to social inequality (oviously, I expect $\beta>0$ ).

Furthermore, all of the specifications shown below include a full set of country $\times$ surveyyear fixed effects, denoted by $\psi_{j[i] t}$ in the equation above. The fixed effects will pick up any systematic differences across countries and years, even if not directly observable in the data at hand. Most importantly, perhaps, note that the inclusion of these fixed effects will net out any existing differences across countries and time in the objective, aggregate level of wage inequality. Moreover, most of the regression specifications shown below will add a few individual-level control variables, denoted by $x_{i t}$ in equation (1). Because most of the available controls at the individual level are potentially endogenous in the current context, however, I will only include few such controls; namely: age, gender, and distributional norms. ${ }^{12}$ A second, more practical but no less important issue is the fact that there is a considerable amount of missing information with respect to many of these potential controls (due to both nonresponse and, again, to the fact that many potentially interesting controls do not appear consistently in all four rounds of the survey). Thus, the inclusion of additional controls would also lead to an often much smaller, and potentially very selective, subsample available for the empirical analysis. ${ }^{13}$

That said, there is of course a similar concern with inequality perceptions and distributional norms being endogenous as well. This concern is more difficult to deal with empirically, and it is therefore held back until section 4.3 below.

\subsection{Stacking the Data to Estimate Average Effects within Groups of Similar Items}

With a total of forty-nine distinct survey items, there are almost too many potentially interesting outcome variables. It is therefore desirable to have a succinct way to estimate some kind

\footnotetext{
${ }^{12}$ In other words, most potential control variables at the individual level are suspect of being influenced by inequality perceptions, implying that specifications including these variables as controls would potentially bias the estimate of parameter $\beta$ (i.e. these variables probably constitute "bad controls" in the language of Angrist and Pischke, 2008). For example, one can imagine that individuals who have been socialized to have a strong belief in non-meritocratic principles might choose a different educational track or occupation than those who believe that these mechanisms are not very important.

${ }^{13}$ Nonetheless, appendix table A.3 shows a few selected estimates based on a larger set of individual-level controls. Reassuringly, the comparison shows that the inclusion of additional controls does not have a large impact on the interesting parameter estimates.
} 
of average effects across items that focus on the same broader conceptual issue.

For this reason, I will focus, for most of the items considered in the empirical analysis, on estimates that rely on data stacked across several survey items rather than reporting estimates for single items. In the case where the estimation is based on stacked data, I thus focus on parameter estimates derived from a regression model with a slightly different structure:

$$
y_{i c t}=\alpha+\beta G_{i t}^{\text {actual }}+\gamma x_{i t}+\psi_{j[i] t}+\epsilon_{i c t},
$$

with $y_{i c t}$ denoting outcome $y$ of individual $i$ in year $t$ and for item $c$ belonging to some larger group of related items $c=1, \ldots, C$; with the total number of items $C$ being larger than one (if there is only a single item, we are back to equation (1)). A first thing to note is that this procedure would - if all the items grouped together were available for exactly the same set of observations - scale up the original sample size by a factor exactly equal to the number of items grouped together. ${ }^{14}$ However, in practice, because most of the items considered in the analysis do not appear in all four years of the survey (less than a quarter of all the items considered), because items appear in different rounds of the survey, and because of different nonresponse patterns across items, items which appear in more rounds of the survey will implicitly be given more weight than those that appear in fewer rounds (a similar argument applies to differences in the number of observations due to potentially different nonresponse patterns). The fact that relatively few items are observed in all four rounds of the survey is also the main reason why I cannot simply use average outcomes as the dependent variable - which would otherwise be the more natural way of aggregating several items together.

In those specifications where several items are stacked together in the way described above, I report standard errors clustered by individual to take the fact that the data contain repeated observations from the same person into account. At the same time, clustered standard errors will also correct for the inflation of the sample size due to stacking various outcomes from the same individuals (note that observations for different outcomes but the same individual have exactly the same values on all the regressors). ${ }^{15}$

\footnotetext{
${ }^{14}$ For example, if there were three (i.e. $C=3$ ) survey questions relating to the same conceptual subject, and if all three items were observed for exactly the same set of observations, then stacking the data would result in a sample exactly three times as large as the original sample size.

${ }^{15}$ In fact, if the items were perfectly correlated with each other within any given individual, then this procedure would simply duplicate the information already available in the original data. This would mechanically deflate
} 
The main practical advantage of this procedure is that it allows me to reduce the dimensionality of the data at hand considerably. Specifically, instead of reporting estimates for each of the 49 distinct items listed in table 1, the results reported below focus on 14 different outcomes only (these outcomes mostly represent groups of items or, in a few exceptional cases, single items).

\subsection{Two-Stage Least Squares Estimates}

One additional concern with simple OLS estimates of $\beta$ based on equation (1) is the potential endogeneity of inequality perceptions due to attitudes about social inequality and inequality perceptions being determined simultaneously. Thus, in estimating the effect of inequality perceptions on attitudes, ideally one has to net out the potential reverse effect, running from attitudes to inequality perceptions.

To account for this potentially relevant issue, I will also present two-stage least squares (2SLS) estimates of the effect of inequality perceptions on individuals' attitudes to social inequality. I will use region-within-country means of subjective inequality perceptions as instrument for an individual's inequality perceptions. ${ }^{16}$ The main argument underlying this instrument is that individual inequality perceptions are most likely influenced by the perceptions of people around them, such as their colleagues at work, their neighbors, or their relatives. At the same time, individual-level perceptions arguably have a negligible effect on mean perceptions in a given region. Even though somewhat less obvious, it might also be reasonable to assume that mean inequality perceptions have no direct effect on individual attitudes to social inequality. ${ }^{17}$ The associated first-stage regression thus takes the following basic form:

$$
G_{i t}^{\text {actual }}=\pi_{0}+\pi_{1} \bar{G}_{k[i] t}^{\text {actual }}+\pi_{2} x_{i t}+\psi_{j[i] t}+\varepsilon_{i}
$$

conventional standard errors, but standard errors clustered by individual would take properly account of this issue.

${ }^{16}$ Dustmann and Preston (2001), for example, propose a similar logic for using an instrument at a higher level of spatial aggregation in their study on the effect of immigrants inflows on natives' attitudes to immigration.

${ }^{17}$ That is, it is implicitly assumed that the instrument has only an indirect effect on the endogenous variable. In the context here, this assumption implies that region-within-country means of inequality perceptions have no direct effect on the outcome(s) other than through their effect on individual-level inequality perceptions. One potential concern with the specific instrument proposed here is that variation in the instrument might also reflect regional differences in the effective level of inequality (which are otherwise not taken into account in the analysis). In that case, the 2SLS estimates are likely to overestimate the effect of inequality perceptions on attitudes. 
with $G_{i t}^{\text {actual }}$ denoting individual-level perceptions of inequality, and with $\bar{G}_{k[i] t}^{\text {actual }}$ denoting mean inequality perceptions in region-within-country $k$ and survey-year $t$, which is used as instrument for individual-level inequality perceptions. The remaining regressors in equation (3) are the same as those discussed in the context of equation (1) above. Specifically, note that it is still possible to control for country fixed-effects because there is within-country variation in the instrument (i.e. $K>J$ ). As usual, $\pi_{1}$ and its associated standard error are informative about the strength of the instrument, and the tables below will report the F-statistic associated with the null hypothesis that the instrument has no partial effect on the endogenous variable.

\section{Results}

\subsection{Beliefs about the Causes of Economic Success}

The first set of estimates, shown in table 3, relates to individuals' beliefs about the causes of economic success, and I start with the results for individuals' beliefs about the reasons for getting ahead. In this and the following two tables, all estimates are based on groups of several survey items, as discussed in section 4.1 above (the exact number of items which are grouped together is noted in the bottom of each table).

\section{Table 3}

The first five columns report estimates of the partial effect of inequality perceptions on people's belief that non-meritocratic mechanisms are important in determining individuals' wages. The following five columns report analogous estimates related to individuals' beliefs that meritocratic mechanisms determine differences in pay. In each of the two panels, the first three columns report OLS estimates, while the remaining two columns show the corresponding 2SLS estimates. For each point estimate reported (in this and all of the following tables), I also present (in brackets) an estimate of the approximate elasticity, evaluated at mean values, of the respective outcome measure with respect to individual-level inequality perceptions.

The estimate reported in the first column of table 3 is from a regression which includes the full set of country $\times$ survey-year fixed effects but no other controls. This first specification yields a positive and highly significant point estimate, implying that a higher perceived level of 
inequality is associated with a stronger belief that non-meritocratic mechanisms are important in determining wages in one's country of residence. The second column adds the two individuallevel controls (i.e. age and gender), resulting in a somewhat smaller, yet still significant estimate of inequality perceptions. However, both estimates imply a small effect, if judged by the implied elasticity. I add individual distributional norms as an additional individual-level regressor in the third column. This variable clearly appears to be important, as the point estimate on inequality perceptions from the third column is as much as $80 \%$ larger than the corresponding estimate from the specification that does not include distributional norms as a control variable (i.e. the point estimate increases from 0.08 to 0.146 ). The larger point estimate notwithstanding, however, note that the approximate elasticity remains quite small (equal to about 0.031).

Next, column 4 reports 2SLS estimates of the full specification, instrumenting inequality perceptions with region-within-country means of inequality perceptions. ${ }^{18}$ This yields an even larger point estimate of about 0.188. However, this larger point estimate goes hand in hand with a much larger robust standard error, resulting in a statistically insignificant point estimate. Finally, I report 2SLS estimates in the fifth column in which I instrument for both inequality perceptions and distributional norms, with the instrument for the latter being the regionwithin-country mean of individual-level distributional norms (essentially mirroring the logic used to justify the instrument for individual inequality perceptions). The point estimate based on this final specification equals 0.173 , close to the estimate from column 4 , and implying an approximate elasticity of about 0.037 . As in the preceding column, this point estimate comes with a comparatively large robust standard error of 0.142 and, consequently, this final point estimate also turns out to be statistically insignificant. ${ }^{19}$

The remaining five columns of table 3 report analogous estimates for individual's beliefs about the importance of meritocratic mechanisms in determining individual wages. There is a somewhat more interesting pattern of results here, insofar as the first two columns indicate that a higher level of inequality is associated with a stronger belief into meritocratic mecha-

\footnotetext{
${ }^{18}$ The table also reports, in curly brackets, the F-statistic associated with the first-stage effect of the instrument(s) on the endogenous variable (i.e. individual-level inequality perceptions).

${ }^{19} \mathrm{I}$ have re-estimated the specifications reported in columns 1 to 5 of table 3 , removing the two items with the lowest mean values. The two excluded items are the following: "A person's religion" and "the part of the country a person comes from". Estimates using the reduced set of items are shown in appendix table A.2. These additional estimates turn out to be larger than those using the full set of items, but with similar-sized standard errors (although they are based on a smaller sample).
} 
nisms being important in determining individual pay, while the remaining three columns (which include distributional norms as a control) indicate that higher inequality perceptions induce a weaker belief into the importance of meritocratic mechanisms. Thus, the more demanding specifications point to a negative, though rather weak effect (implied elasticity of about -0.039 to -0.036) of inequality perceptions on the belief that meritocratic principles are important in determining pay.

Table 4

Moving on to individuals' beliefs about a potential functional role played by inequality, by setting incentives for economic agents, table 4 reports estimates quantifying how inequality perceptions impact individuals' beliefs about a potential incentivizing effect of inequality, both at the individual and the aggregate level. ${ }^{20}$ The first three columns of table 4 show that there appears to be an effect of inequality perceptions on the belief that inequality serves as in incentive for individual effort. The two OLS estimates are small, and only the estimate from the specification that does not include distributional norms is statistically significant, but the 2SLS estimate turns out again to be significant and much larger than the corresponding OLS estimate. Also, this estimate implies a rather substantive elasticity of about 0.11. Interestingly, but also somewhat contradictory, the remaining three columns of table 4 show that there is a negative effect of inequality perceptions on the belief that inequality is necessary for an economy's success as a whole at the same time. Both OLS and 2SLS estimates are statistically significant, consistently negative, and also quite large in economic terms. Controlling for distributional norms, the point estimates imply an elasticity of -0.168 to -0.147 .

\section{Table 5}

Additional complementary evidence on individuals' attitudes towards different pay norms is reported in table 5. As for individuals' beliefs about the reasons for getting ahead, it is possible to distinguish between meritocratic and non-meritocratic pay norms. Not surprisingly, the corresponding estimates indicate that higher inequality perceptions are associated with a

\footnotetext{
${ }^{20}$ To save space, table 4 and all of the following tables only show estimates based on the key specifications (i.e. OLS estimates both with and without controlling for individual distributional norms as well as 2SLS estimates based on instrumenting both inequality perceptions and distributional norms); there are thus fewer columns from table 4 onwards than in table 3.
} 
stronger belief in non-meritocratic pay norms, at least when distributional norms are held constant (note that the relevant OLS estimate switches its sign in this case, depending on whether distributional norms are held constant or not). Conditional on the inclusion of distributional norms, however, OLS and 2SLS estimates again appear consistent with each other (and again, 2SLS estimates turn out considerably larger than their OLS counterparts). Including distributional norms as a control variable also makes a difference regarding the effect of inequality perceptions on meritocratic pay norms. While the OLS estimate for the simpler specification turns out positive, it becomes negative once distributional norms are also taken into account. Moreover, note that OLS and 2SLS estimates appear inconsistent in this case, with the OLS estimate suggesting a negative effect, and the corresponding 2SLS estimate pointing to a positive effect of inequality perceptions on the importance of meritocratic pay norms.

\subsection{The Perception of Chances and Risks Associated with Inequality}

I next discuss estimates relating to the chances and risks that might be perceived as associated with a given level of inequality. Specifically, the first three columns of table 6 report estimates for individuals' beliefs that they stand a good chance of improving their standards of living. This item is clearly related to the outcomes considered in the preceding subsection, as it is very likely that individuals perceive their own chance of upward mobility to be less pervasive when they think that wages are substantively driven by non-meritocratic mechanisms. Arguably, it is also related to individuals' wage satisfaction, which is considered in the second panel of table 6 below.

Indeed, the estimates from the first three columns show that inequality perceptions are negatively and significantly associated with the belief that one stands a good chance of improving his or her standard of living. Also, in this case, the 2SLS estimate turns out to be of similar size as the corresponding OLS estimate using the full set of controls, and the estimates imply a relatively large sized effect in substantive terms (approximate elasticity of about -0.14 to -0.13 , when controlling for distributional norms).

\section{Table 6}

Moreover, given that individuals with high levels of perceived wage inequality appear to put considerably more emphasis on non-meritocratic determinants of wages, as shown in section 
5.1 above, one would presumably also expect that these individuals are less satisfied with their own compensation. Not surprisingly, then, the remaining three columns of table 6 show that individual wage satisfaction is decreasing in the perceived level of wage inequality. As before, the OLS estimate is considerably larger when using the full set of controls, implying quite a large elasticity of wage satisfaction with respect to inequality perceptions of about -0.113 . Instrumenting does not change the qualitative result, but it yields a much larger point estimate (the 2SLS estimate equals -0.875, compared to the corresponding OLS estimate of -0.419); which also implies a larger elasticity of about -0.237 .

\section{Table 7}

The first panel of table 7 shows estimates for people's overall normative assessment of inequality in their country of residence. Considering the results discussed so far, it is probably not surprising to find that inequality perceptions have a strong and highly significant effect on the individual perception that income differences in one's country are too large. In fact, both OLS and 2SLS estimates are statistically significant and they imply a comparatively large approximate elasticity of about 0.134 and 0.215 , respectively, when holding distributional norms constant (note that the OLS estimate without controlling for distributional norms is still significant, but only about half the size of the OLS estimate including distributional norms as a control).

The second part of table 7 shows that individuals with higher inequality perceptions also tend to perceive a higher level of conflict in their society. Again, the inclusion of distributional norms turns out to be important for the qualitative result, as the OLS estimate without the inclusion yields an insignificant point estimate, but adding distributional norms turns the OLS estimate significant (point estimate of -0.003 and 0.176 , respectively).

\subsection{The Role of Government and Support of Progressive Taxation}

The next set of estimates, presented in table 8, documents the effect of inequality perceptions on individuals' views about the appropriate role of the state with respect to distributional issues as well as to their support of progressive taxation. ${ }^{21}$

\footnotetext{
${ }^{21}$ There is a closely related, voluminous empirical literature on the determinants of preferences for redistribution. See Alesina and Giuliano (2011) for a survey of this literature.
} 


\section{Table 8}

Consistent with the previous results, the first three columns of table 8 show that a higher level of perceived inequality is statistically significantly associated with stronger support for government intervention. That is, people who perceive a high level of wage inequality appear to be considerably more supportive of intervention by the state. Both OLS and 2SLS estimates are statistically significant and positive and, again, including distributional norms as a control yields a much larger OLS estimate and instrumenting yields a still larger point estimate. When controlling for distributional norms, both OLS and 2SLS estimate imply a relatively large quantitative effect of inequality perceptions (as indicated by the comparatively large approximate elasticity of about 0.097 and 0.188 , respectively).

The remaining three columns of table 8 show estimates on individuals' support of progressive taxation. Again, I find that there is a positive, and statistically highly significant, effect of inequality perceptions on the support of progressive taxation. The pattern is similar to the preceding results concerning the role of the state; with the OLS estimate approximately doubling when distributional norms are included as a control, and with a yet higher 2SLS estimate. Also, the economic size of the estimates is quite large, with an approximate elasticity about 0.11 to about 0.165 , depending on the specification.

\subsection{Political Preferences and Political Participation}

The final set of estimates, reported in table 9, focuses on the effect of inequality perceptions on individuals' political preferences as well as their general political participation. The first three columns of table 9 report estimates for respondents' identification with the political right (that is, higher values on the dependent variable signify a stronger identity with the political right), while the remaining three columns focus on individuals' more general degree of political participation, measured by a single item asking about participation at the last election held in a respondent's country of residence.

\section{Table 9}

Not surprisingly, and consistent with the results presented so far, the first three columns of table 9 show that higher inequality perceptions are associated with people being significantly 
less (more) likely to state that they identify with the political right (left). Again, controlling for individual distributional norms, both OLS and 2SLS estimate imply quite a large effect of inequality perceptions on political preferences (with an approximate elasticity of about -0.102 and -0.309 , respectively).

Finally, the evidence with respect to voting - as a measure of an individual's general political participation - is somewhat mixed. The two OLS estimates suggest that political participation is increasing in an individual's inequality perception, while the 2SLS estimate turns out to be small and statistically insignificant. If anything, then, a high perceived level of wage inequality seems to increase political participation.

\section{Conclusions}

In this paper, I use a simple yet intuitive empirical measure of individual-level inequality perceptions to estimate how these subjective perceptions affect individuals' attitudes to and beliefs about social inequality. Using a broad variety of different outcomes reflecting the diverse dimensions of attitudes to social inequality, the empirical analysis shows that a higher level of perceived wage inequality is statistically significantly associated with a weaker belief into the proper functioning of (labor) markets. Specifically, I find that individuals who perceive wage inequality to be high tend to be less (more) likely to believe that wage differentials are driven by meritocratic (non-meritocratic) principles. Consistent with previous empirical evidence, these individuals are also less likely to be satisfied with their own compensation from work. Taken together, these results suggest that a high perceived level of wage inequality has the potential to undermine the legitimacy of market outcomes. The results are also consistent with the argument that there is a feedback process running from (the perception of) inequality to attitudes to social inequality.

I further show that this result is robust to the use of an instrumental-variable estimation strategy which uses regional means of inequality perceptions as an instrument for individuallevel inequality perceptions. In general, 2SLS estimates turn out to be larger (in absolute terms) yet mostly consistent with the corresponding OLS estimates. Moreover, the implied approximate elasticities of attitudes and beliefs with respect to inequality perceptions reveal that the quantitative size of the estimates effects appear to be plausible. While most of the 
estimates describing the effect of inequality perceptions on attitudes to social inequality are statistically significant, most of the corresponding elasticities appear to be small or of moderate size.

Finally, the results presented in this paper also add to the available empirical evidence showing that subjective perceptions of economic phenomena shape individuals' attitudes and beliefs. The results of this paper show that attitudes to and beliefs about economic inequality are, in part, influenced by individuals' perception of the prevailing level of wage inequality in their country of residence. This in turn implies that changes in inequality might indeed bring about corresponding changes in attitudes towards social inequality. 


\section{References}

Alesina, A. and Angeletos, G. (2005). Fairness and Redistribution. American Economic Review, 95(3), 960-980.

Alesina, A. and Giuliano, P. (2011). Preferences for Redistribution. In Handbook of Social Economics, volume 1A, chapter 4. Elsevier.

Alesina, A., Cozzi, G., and Mantovan, N. (2012). The evolution of ideology, fairness and redistribution. Economic Journal, 122(565), 1244-1261.

Angrist, J. D. and Pischke, J.-S. (2008). Mostly harmless econometrics: An empiricist's companion. Princeton University Press.

Atkinson, A. B. (2008). The changing distribution of earnings in OECD countries. Oxford University Press.

Bénabou, R. and Tirole, J. (2006). Belief in a just world and redistributive politics. Quarterly Journal of Economics, 121(2), 699-746.

Bjørnskov, C., Dreher, A., Fischer, J. A., Schnellenbach, J., and Gehring, K. (2013). Inequality and happiness: When perceived social mobility and economic reality do not match. Journal of Economic Behavior \& Organization, 91, 75-92.

Card, D., Mas, A., Moretti, E., and Saez, E. (2012). Inequality at Work: The Effect of Peer Salaries on Job Satisfaction. American Economic Review, 102(6), 2981-3003.

Chambers, J. R., Swan, L. K., and Heesacker, M. (2014). Better off than we know distorted perceptions of incomes and income inequality in America. Psychological Science, 25(2), 613-618.

Charness, G. and Kuhn, P. (2007). Does pay inequality affect worker effort? Experimental evidence. Journal of Labor Economics, 25(4), 693-723.

Clark, A. and Oswald, A. (1996). Satisfaction and comparison income. Journal of Public Economics, 61(3), 359-381.

Clark, A. and Senik, C. (2010). Who compares to whom? The anatomy of income comparisons in Europe. Economic Journal, 120(544), 573-594.

Clark, A. E., Westergård-Nielsen, N., and Kristensen, N. (2009). Economic satisfaction and income rank in small neighbourhoods. Journal of the European Economic Association, 7(2/3), $519-527$.

Clark, A. E., Masclet, D., and Villeval, M. C. (2010). Effort and comparison income: Experimental and survey evidence. Industrial \&5 Labor Relations Review, 63(3), 407-426.

Cornelissen, T., Himmler, O., and Koenig, T. (2011). Perceived unfairness in CEO compensation and work morale. Economics Letters, 110(1), 45-48.

Cruces, G., Truglia, R., and Tetaz, M. (2013). Biased perceptions of income distribution and preferences for redistribution: Evidence from a survey experiment. Journal of Public Economics, 98, 100-112.

Di Tella, R., Galiani, S., and Schargrodsky, E. (2007). The formation of beliefs: Evidence from the allocation of land titles to squatters. Quarterly Journal of Economics, 122(1), 209-241. 
Dustmann, C. and Preston, I. (2001). Attitudes to ethnic minorities, ethnic context and location decisions. Economic Journal, 111(470), 353-373.

Ferrer-i-Carbonell, A. (2005). Income and well-being: an empirical analysis of the comparison income effect. Journal of Public Economics, 89(5-6), 997-1019.

Gemmell, N., Morrissey, O., and Pinar, A. (2004). Tax perceptions and preferences over tax structure in the United Kingdom. Economic Journal, 114(493), F117-F138.

Giuliano, P. and Spilimbergo, A. (2014). Growing up in a recession. Review of Economic Studies, 81(2), 787-817.

ISSP Research Group (2014a). International Social Survey Programme: Social Inequality I-IV - ISSP 1987-1992-1999-2009. GESIS Data Archive, Cologne. ZA5890 Data File Version 1.0.0.

ISSP Research Group (2014b). International Social Survey Programme: Social Inequality I-IV add on - ISSP 1987-1992-1999-2009. GESIS Data Archive, Cologne. ZA5891 Data file Version 1.1.0.

Kuhn, A. (2011). In the eye of the beholder: Subjective inequality measures and individuals' assessment of market justice. European Journal of Political Economy, 27(4), 625-641.

Kuziemko, I., Norton, M. I., and Saez, E. (2015). How elastic are preferences for redistribution? evidence from randomized survey experiments. American Economic Review, 105(4), 14781508.

Luttmer, E. (2005). Neighbors as Negatives: Relative Earnings and Well-Being. Quarterly Journal of Economics, 120(3), 963-1002.

Norton, M. and Ariely, D. (2011). Building a better America - one wealth quintile at a time. Perspectives on Psychological Science, 6(1), 9-12.

Olken, B. (2009). Corruption perceptions vs. corruption reality. Journal of Public Economics, 93(7), 950-964.

Osberg, L. and Smeeding, T. (2006). "Fair" inequality? Attitudes toward pay differentials: the United States in comparative perspective. American Sociological Review, 71(3), 450-473.

Schneider, S. (2012). Income inequality and its consequences for life satisfaction: What role do social cognitions play? Social Indicators Research, 106(3), 419-438.

Schwarze, J. and Härpfer, M. (2007). Are people inequality averse, and do they prefer redistribution by the state? Evidence from German longitudinal data on life satisfaction. Journal of Socio-Economics, 36(2), 233-249.

Senik, C. (2005). Income distribution and well-being: what can we learn from subjective data? Journal of Economic Surveys, 19(1), 43-63.

Verme, P. (2011). Life satisfaction and income inequality. Review of Income and Wealth, 57(1), $111-127$.

Winkelmann, L. and Winkelmann, R. (2010). Does Inequality Harm the Middle Class? Kyklos, 63(2), 301-316. 
Table 1: Descriptive statistics, outcome measures

\begin{tabular}{lllllllll}
\hline & Mean & Sd & Min & Max & & $\mathrm{T}$ \\
\hline
\end{tabular}

(a) Reasons for getting ahead

(i) Non-meritocratic principles

Coming from a wealthy family

$\begin{array}{llllll}2.847 & 1.136 & 1 & 5 & 85,010 & 4 \\ 3.082 & 1.036 & 1 & 5 & 57,118 & 3 \\ 3.484 & 1.006 & 1 & 5 & 85,361 & 4 \\ 2.568 & 1.165 & 1 & 5 & 56,597 & 3 \\ 2.221 & 1.119 & 1 & 5 & 53,116 & 3 \\ 1.868 & 1.029 & 1 & 5 & 55,763 & 3 \\ 1.976 & 0.997 & 1 & 5 & 28,719 & 2 \\ 2.214 & 1.120 & 1 & 5 & 55,855 & 3 \\ 2.234 & 1.058 & 1 & 5 & 27,777 & 2 \\ 2.739 & 1.273 & 1 & 5 & 53,369 & 2\end{array}$

Having well-educated parents

Knowing the right people

Having political connections

A person's race

A person's religion

The part of the country a person comes from

Being born a man or a woman

A person's political beliefs

Have to be corrupt

2.739

$3.876 \quad 0.907$

$3.962 \quad 0.888$

$3.732 \quad 0.864$

$3.934 \quad 0.915$

\begin{tabular}{|c|c|c|}
\hline 1 & 5 & 58,967 \\
\hline 1 & 5 & 58,523 \\
\hline 1 & 5 & 30,477 \\
\hline 1 & & 58,813 \\
\hline
\end{tabular}

Hard work

(b) Incentivizing effect of inequality

(i) At the individual level

To get people to work hard

No extra responsibility at work

$\begin{array}{llllll}2.891 & 0.851 & 1 & 4 & 11,675 & 2 \\ 3.811 & 1.017 & 1 & 5 & 30,344 & 2 \\ 3.677 & 1.070 & 1 & 5 & 30,292 & 2 \\ 3.794 & 1.106 & 1 & 5 & 56,774 & 3\end{array}$

No objections to extra qualification

2.575

1.159

3.256

1.129

$\begin{array}{llll}1 & 5 & 54,803 & 3 \\ 1 & 5 & 27,378 & 2\end{array}$

Allowing business to make profits

(c) Pay norms ("what should be important for pay")

(i) Non-meritocratic norms

What is needed to support a family

Whether someone has children to support

3.438

3.263

1.073

1.151

$\begin{array}{llll}1 & 5 & 72,321 & 3 \\ 1 & 5 & 72,429 & 3\end{array}$

(ii) Meritocratic norms

Number of years spent in education and training

3.579

0.897

3.477

0.897

Whether the job requires super
How well someone does the job

4.156

0.732

4.023

0.796

$\begin{array}{llll}1 & 5 & 72,429 & 3\end{array}$

How hard someone works

4.023

\begin{tabular}{|c|c|c|}
\hline 1 & 5 & 73,275 \\
\hline 1 & 5 & 44,811 \\
\hline 1 & 5 & 72,711 \\
\hline 1 & 5 & 73,265 \\
\hline
\end{tabular}




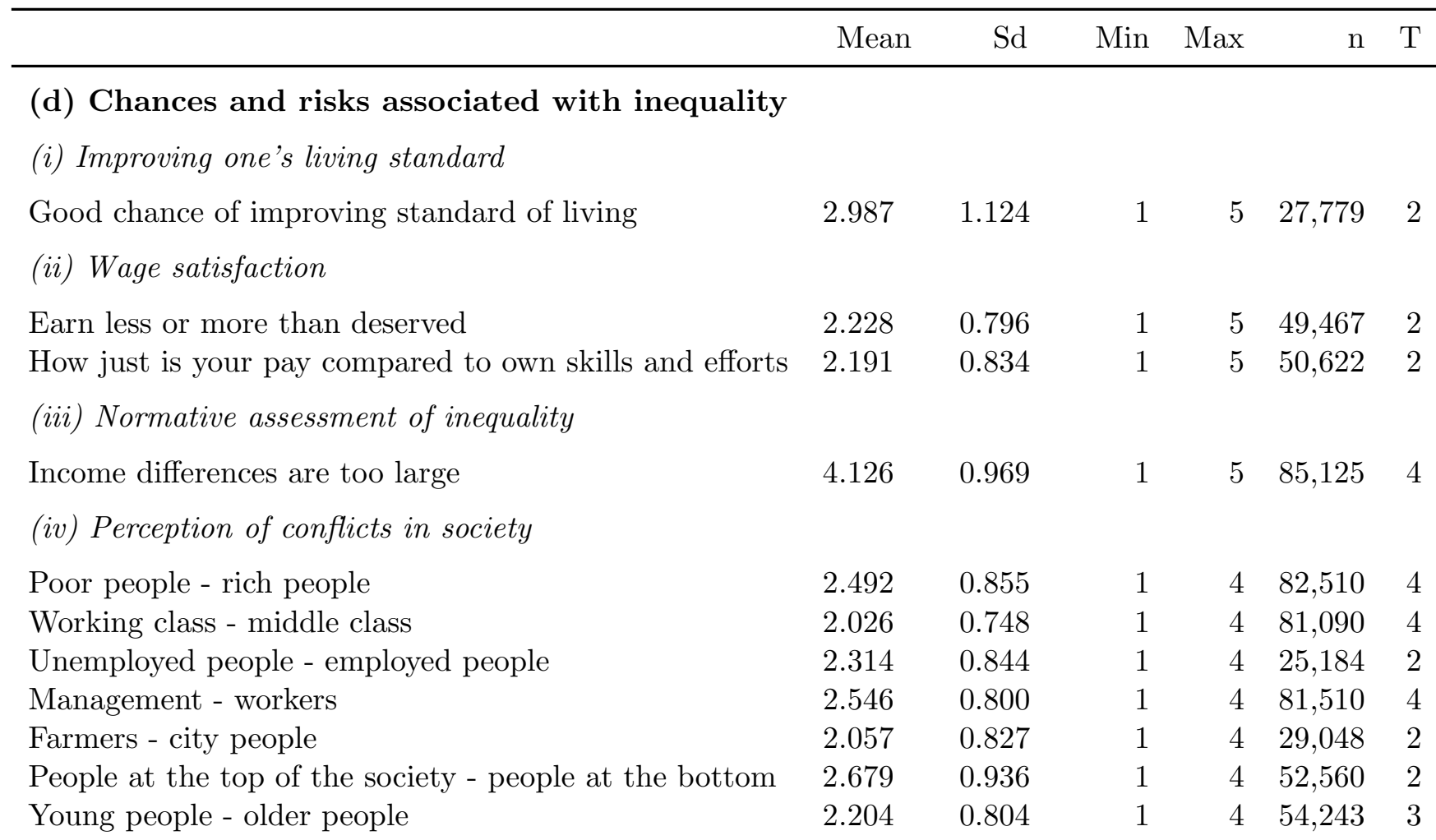

(e) The role of governement and support of progressive taxation

(i) The role of governement

Reduce income differences

Provide chances for poor children to go to university

3.710

4.023

Provide jobs for everyone who wants one

3.846

Provide decent living standard for unemployed

3.697

Spend less on benefits for the poor (-)

Provide basic income for all

2.238

3.635

1.172

0.925

1.156

1.045

1.103

1.233

$\begin{array}{llllll}4.019 & 0.773 & 1 & 5 & 80,642 & 4 \\ 3.337 & 1.090 & 1 & 5 & 53,107 & 3\end{array}$

(ii) Support of progressive taxation

People with high incomes should pay more taxes

Taxes for those with high incomes

(f) Political preferences and political participation

(i) Political identification (with the political right)

Party affiliation (affiliation to a certain party)

$2.907-0.966$

Party affiliation (question on left-right placement)

Party voted in last election

1.004

$\begin{array}{llll}1 & 5 & 33,442 & 4\end{array}$

$\begin{array}{llll}1 & 5 & 12,555 & 3\end{array}$

$\begin{array}{llll}1 & 5 & 14,720 & 4\end{array}$

(ii) Political participation

Voted in last election (yes $=1$ )

0.794

0.405

0

$1 \quad 47,516 \quad 4$

Notes: The table shows descriptives for all the items eventually used as an outcome. The first four columns show, respectively, the mean, the standard deviation, as well as the sample minimum and maximum (note that all variables only take on integer values). The last two columns show the number of observations with valid values (n) as well as the number of years (out of a maximum of four) a given item appeared in the survey (T). 


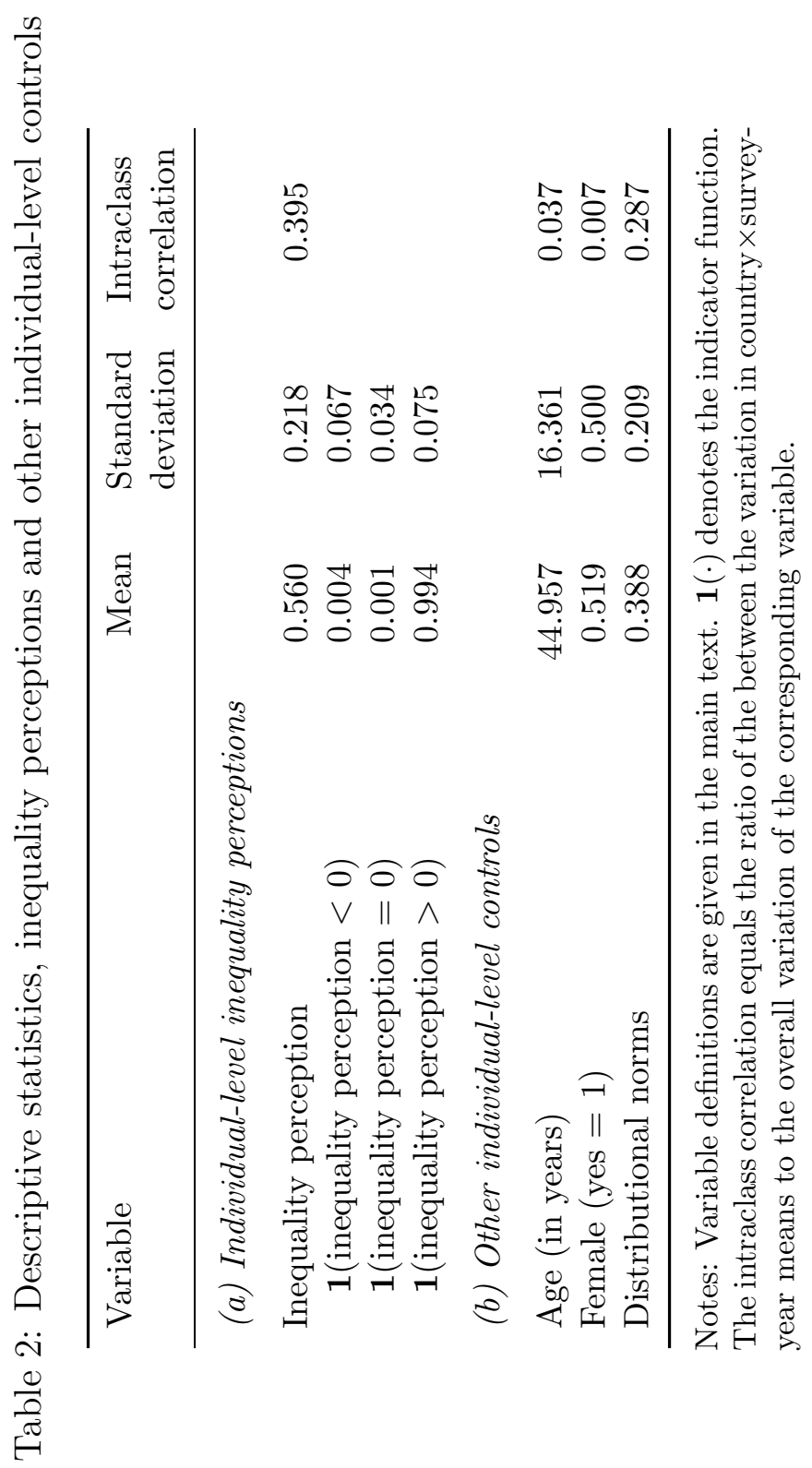




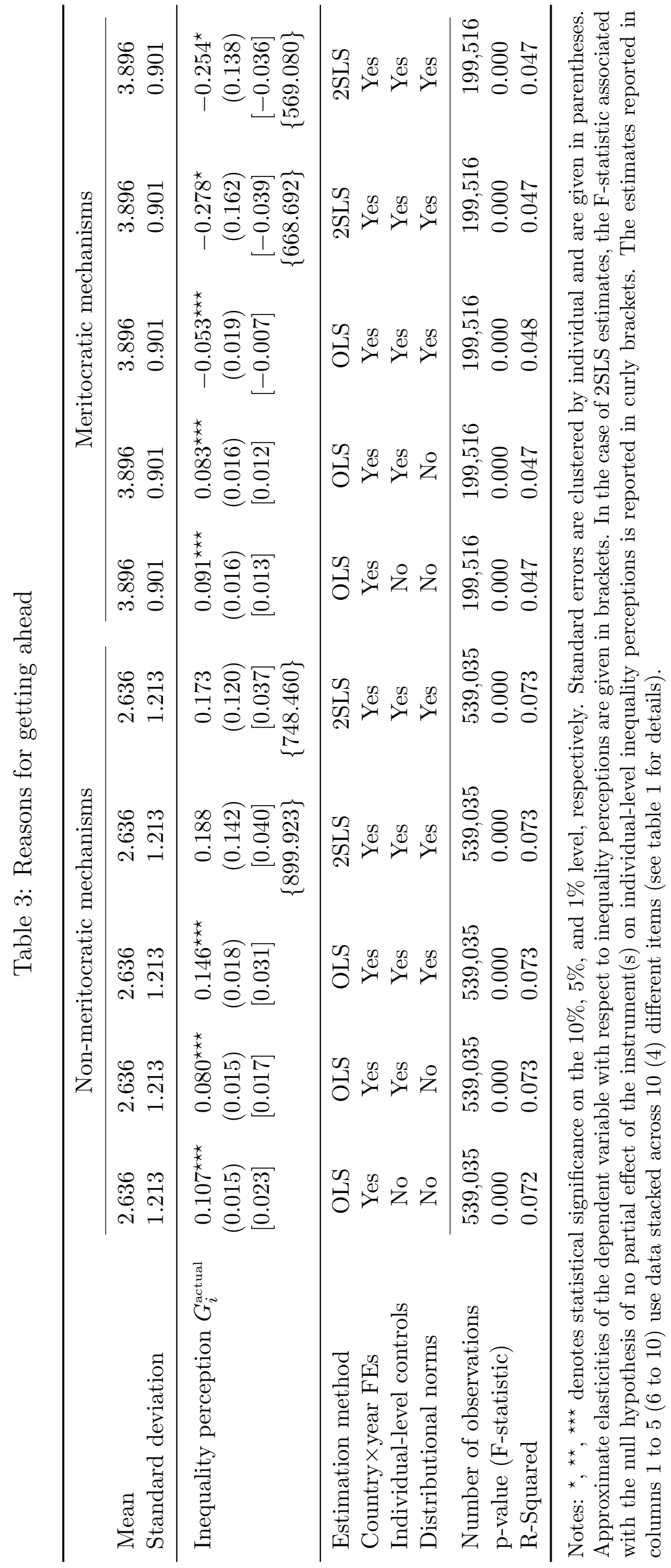




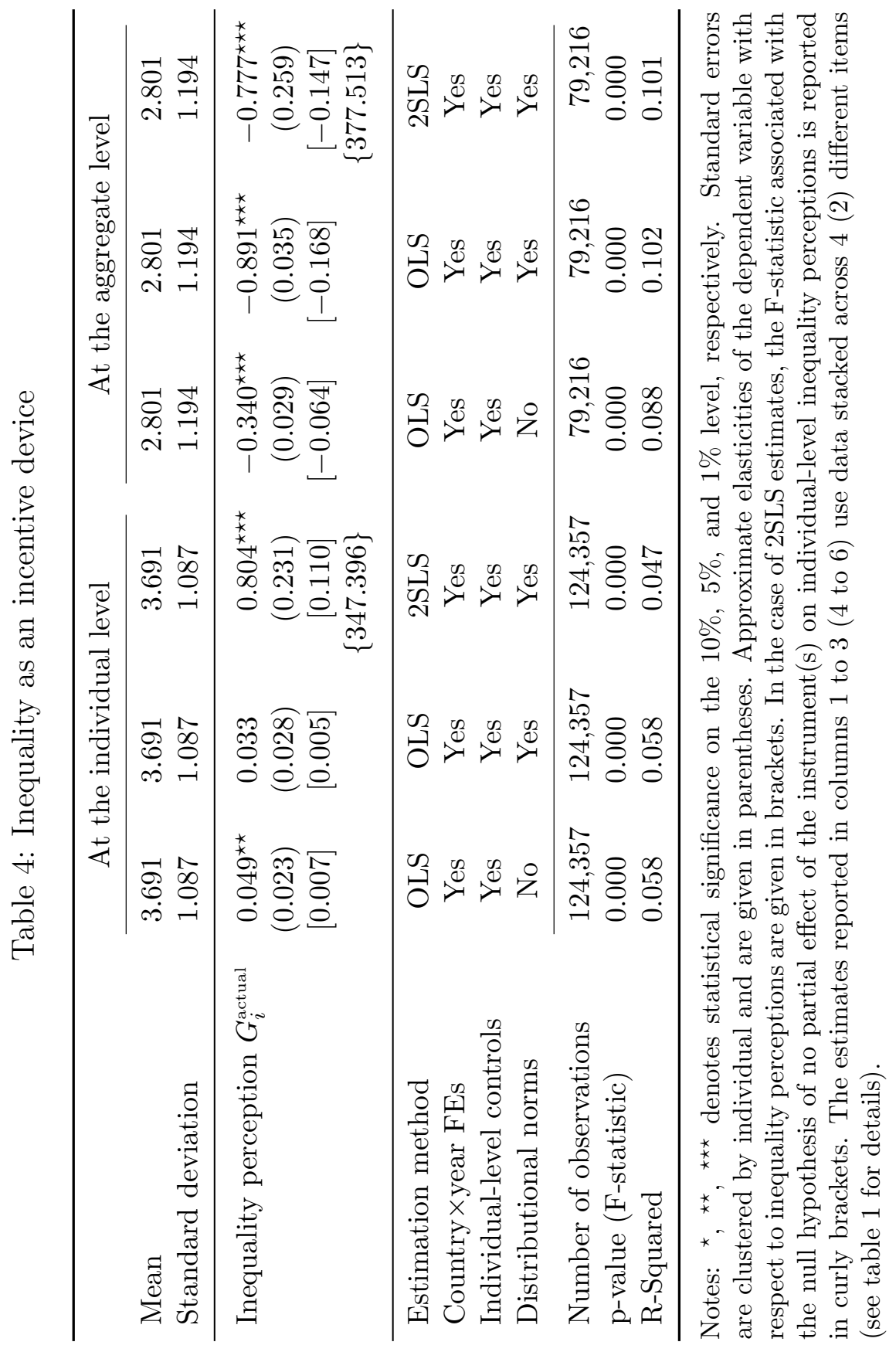




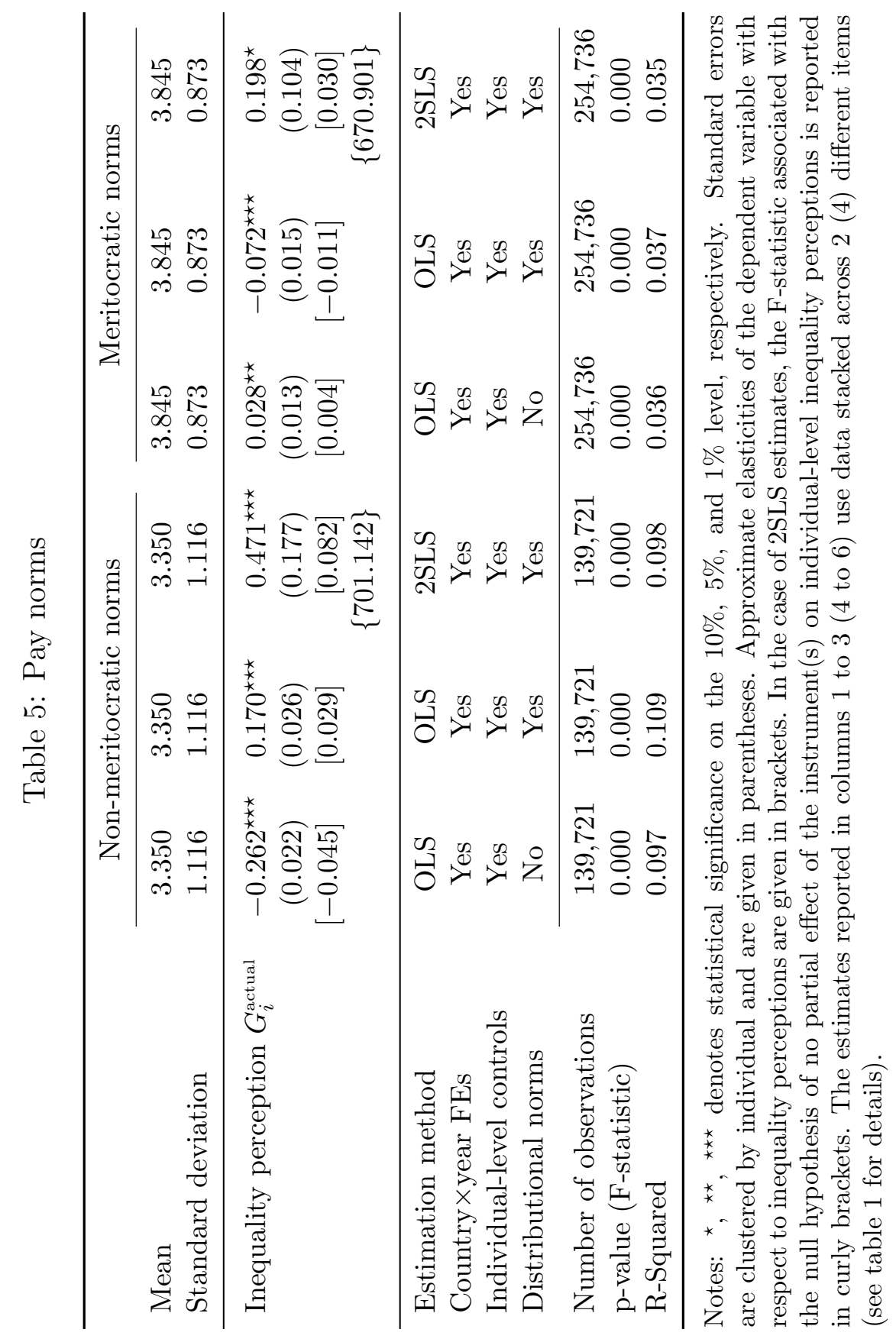




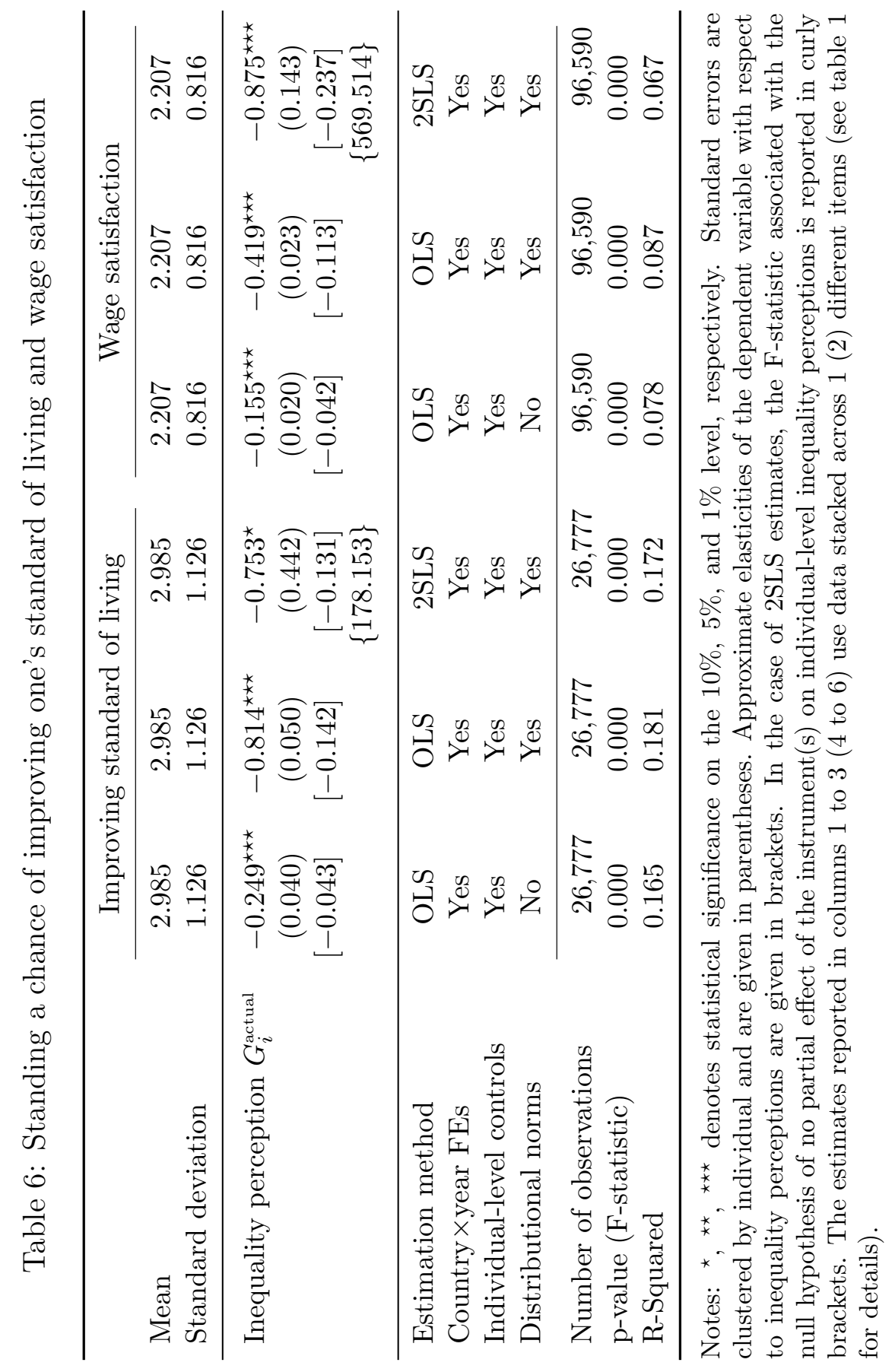




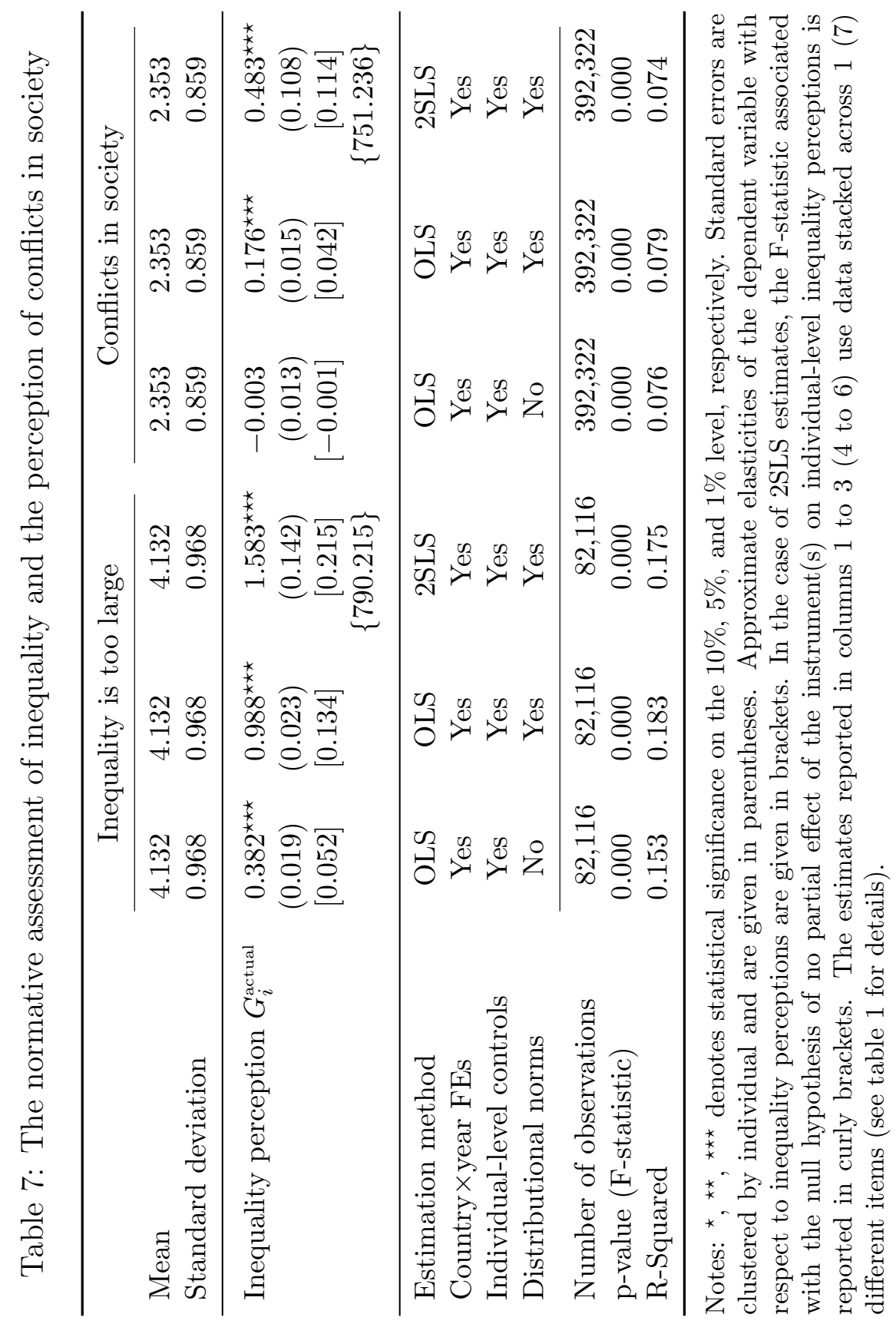




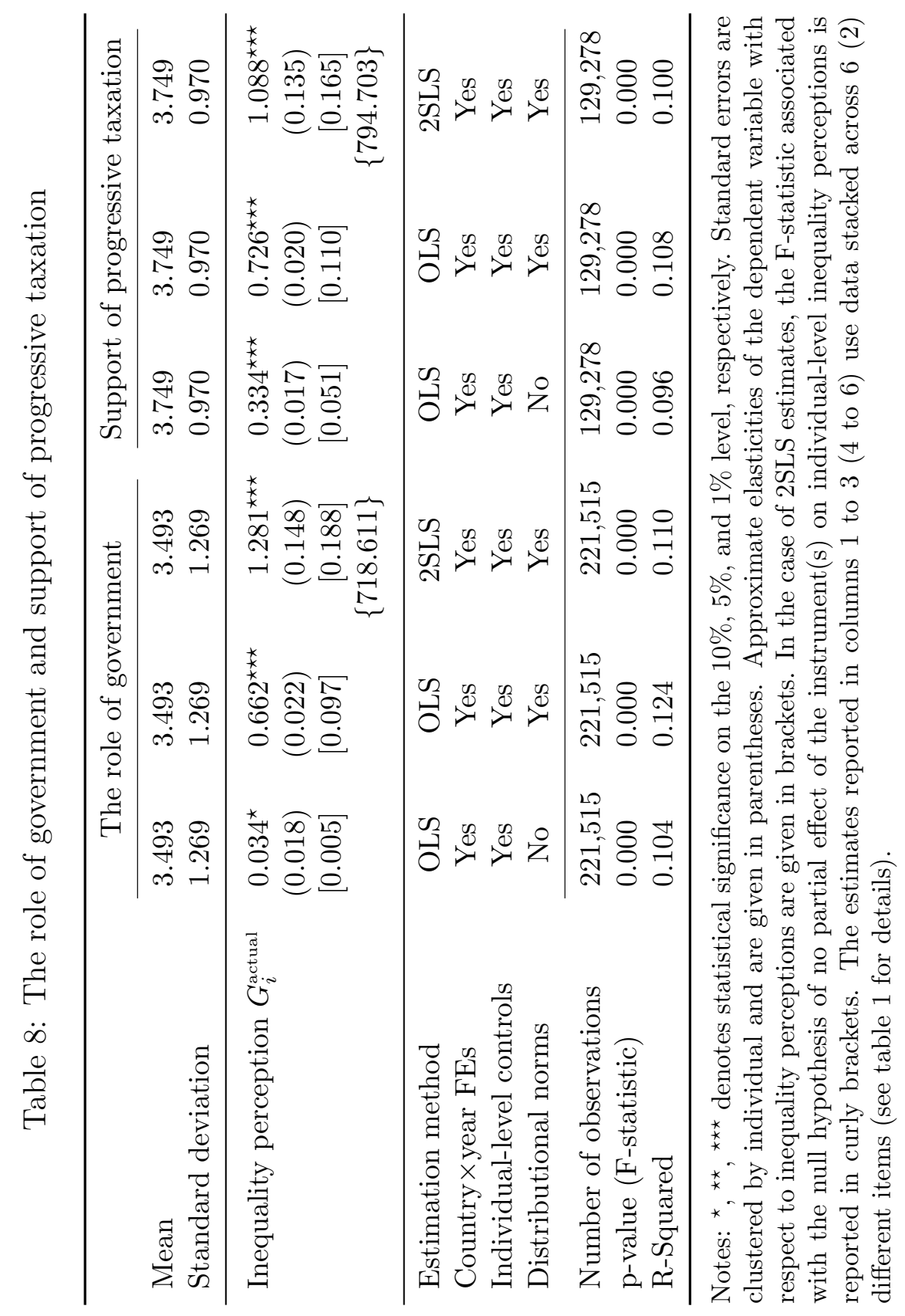




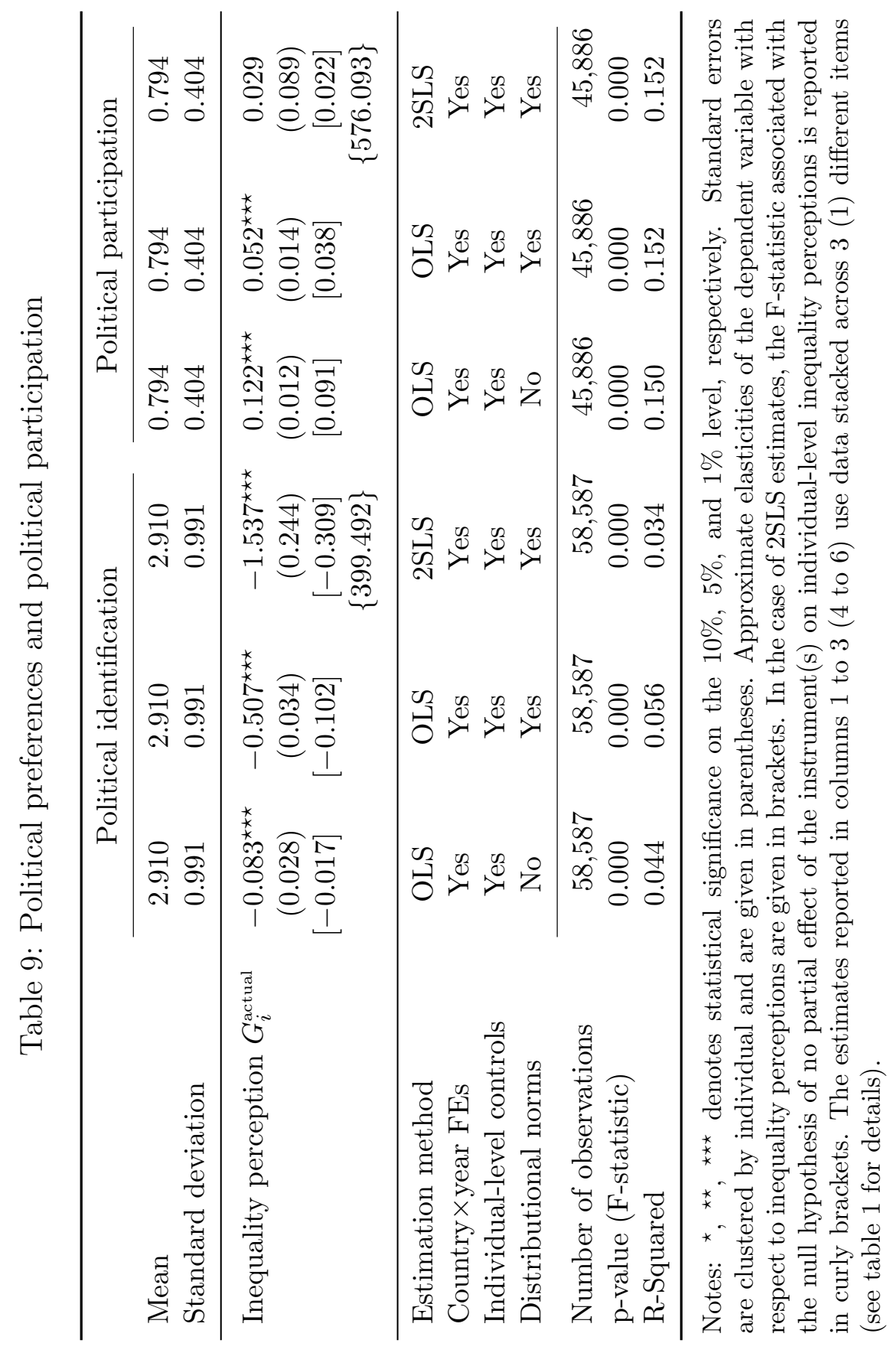




\section{A Additional tables}

Table A.1: Number of observations, by country and year

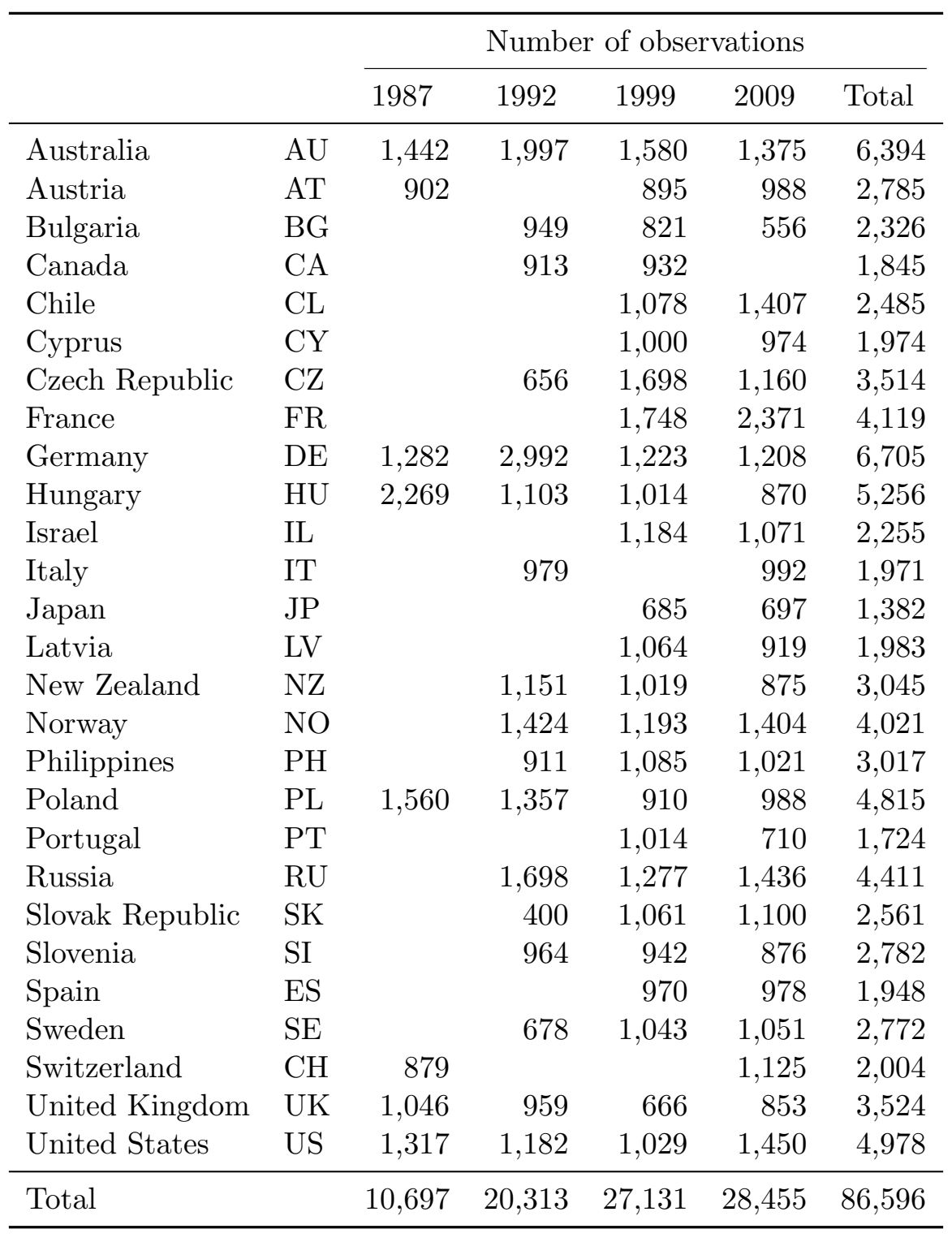

Notes: The table shows the number of observations with nonmissing inequality perceptions. 


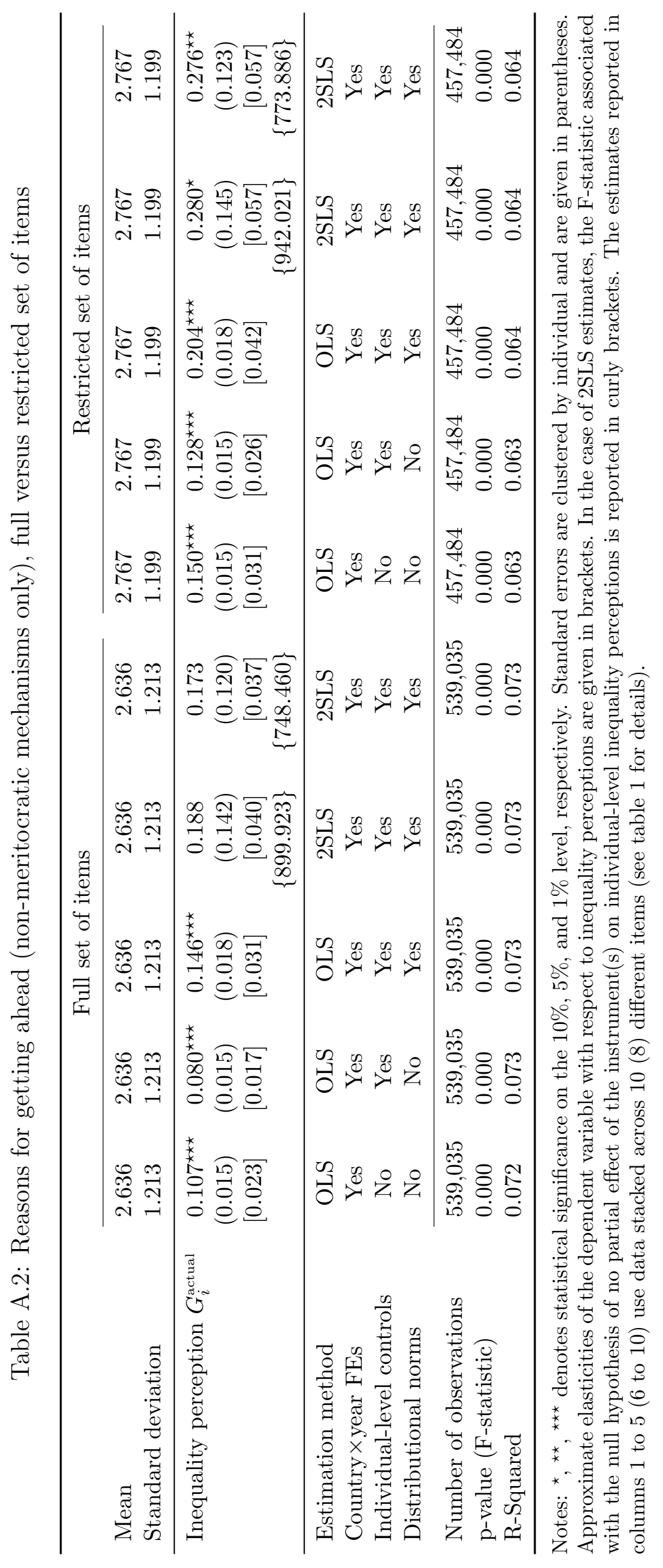




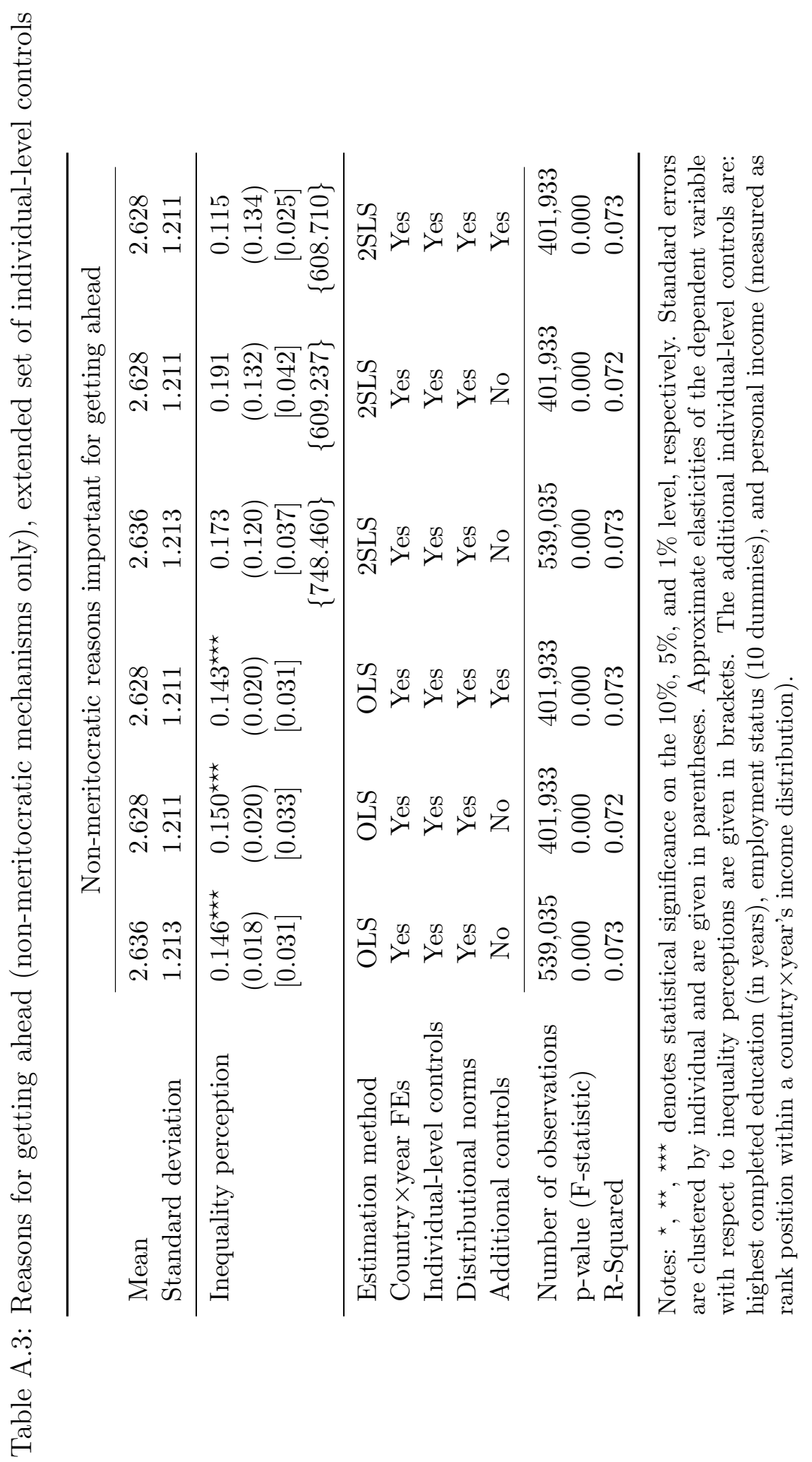

